\title{
Post-femtosecond-assisted Laser-assisted In Situ Keratomileusis Ectasia in a Hyperopic Eye
}

\author{
${ }^{1}$ Dana Garzozi, ${ }^{2}$ Hanna J Garzozi, ${ }^{3}$ Adel Barbara
}

\begin{abstract}
We report on a case of post-femtosecond-assisted laserassisted in situ keratomileusis (LASIK) (FA-LASIK) corneal ectasia, which developed in a young hyperopic male who underwent surgery in both eyes (BE) and eighteen month later, an enhancement procedure in his left eye (LE) due to residual hyperopia.

Ten years later, the patient complained about deterioration of his visual acuity (VA) in his LE. An examination of the eyes and imaging of the cornea revealed post-LASIK ectasia in his LE.

Post-LASIK ectasia in hyperopic eyes has already been reported in few cases, but this is the first report on post-FALASIK ectasia in a hyperopic eye.
\end{abstract}

Keywords: Astigmatism, Ectasia, Hyperopia, Laser, LASIK.

How to cite this article: Garzozi D, Garzozi HJ, Barbara A. Post-femtosecond-assisted Laser-assisted In Situ Keratomileusis Ectasia in a Hyperopic Eye. Int J Kerat Ect Cor Dis 2018;7(2):121-127.

\section{Source of support: Nil}

Conflict of interest: None

\section{INTRODUCTION}

Corneal ectasia is a serious postoperative, sight-threatening complication of LASIK surgery which was first described by Seiler and Quurke. ${ }^{1}$ It is distinguished by a progressive increase in the corneal curvature with progressive steepening and thinning of the cornea. These morphologic changes may lead to increased myopia, astigmatism, and loss of best-corrected visual acuity (BCVA). ${ }^{2}$ The prevalence of corneal ectasia after LASIK surgery is estimated to be between $0.04 \%$ and $0.6 \%,{ }^{3}$ and most reports observed mainly myopic eyes. The pathogenesis of corneal ectasia formation after excimer laser refractive surgery has not been completely determined; however, several preoperative

${ }^{1}$ Resident, ${ }^{2}$ Professor, ${ }^{3}$ Director

${ }^{1}$ Department of Ophthalmology, Assaf Harofeh Medical Center, Tel Aviv University, Tel Aviv, Israel

2,3IVISION, Refractive Surgery Center, Haifa, Israel

Corresponding Author: Dana Garzozi, Resident, Department of Ophthalmology, Assaf Harofeh Medical Center, Tel Aviv University, Tel Aviv, Israel, e-mail: danagarzozi@gmail.com risk factors which may lead to the development of ectasia after LASIK have been thoroughly described in literature and will be discussed subsequently.

\section{CASE REPORT}

In May 2016, a healthy 35-year-old man presented to our facility complaining of visual disturbance in his LE. During anamnesis, the patient reported being hyperopic since an early age and that in 2004, he underwent FALASIK surgery in BE in another facility. Before surgery, his best-corrected spectacle visual acuity (BSCVA) was 6/6 in his right eye (RE) and 6/7.5 partial in the LE. His cycloplegic refraction was +6.00 Diopters (D) 1.75 Cylinder Diopter (CD) 145 in the RE and +6.25 D 0.50 CD 40 in the LE. Biomicroscopy showed normal anterior segment and fundus examination without abnormal pathology in BE and intraocular pressure was measured to be $15 \mathrm{~mm} \mathrm{Hg}$ in BE. Central corneal thickness (CCT) was 505 and $510 \mu \mathrm{m}$, respectively.

Corneal topography (EyeSys Vision, Technologies Inc. Houston, Texas) was performed and demonstrated mild skew deviation in the LE (Fig. 1). An orbscan of the BE (Orbscan II Bausch and Lomb, Inc. Rochester, New York, USA) demonstrated normal values (Fig. 2).

On October 28, 2004, the patient was operated in BE; a flap of $9.5 \mathrm{~mm}$ and $120 \mu \mathrm{m}$ thickness was performed by femtosecond laser. Excimer laser ablation for hyperopia and astigmatism of +5.75 D 1.75 CD 153 was performed in the RE and +5.75 D 0.75 CD 38 in the LE. The optical zone was 5.5 and $5.6 \mathrm{~mm}$ respectively. Ablation depth was $92 \mu \mathrm{m}$ in the RE and $98 \mu \mathrm{m}$ in the LE. Estimated residual corneal thickness was 490 and $485 \mu \mathrm{m}$, respectively.

On postoperative follow-up, the uncorrected visual acuity (UCVA) was between the range of 6/8.5 and 6/10 in the RE, and between $6 / 20$ and 6/40 in the LE.

Sixteen months postsurgery, a residual hyperopia of +2.50 D 1.50 CD 175 was measured in the LE with BSCVA of 6/12 . Axial map topography (EyeSys Vision, Technologies Inc. Houston, Texas) showed a central steepening with skewed radial axis (Fig. 3). Orbscan II (Fig. 4) demonstrated increased posterior oat elevation in the LE (Orbscan II Bausch and Lomb, Inc. Rochester, New York, USA). In March 2006, due to patient dissatisfaction with VA in the LE, an enhancement procedure was done. A flap of $9.0 \mathrm{~mm}$ and $100 \mu \mathrm{m}$ thickness was performed; the 


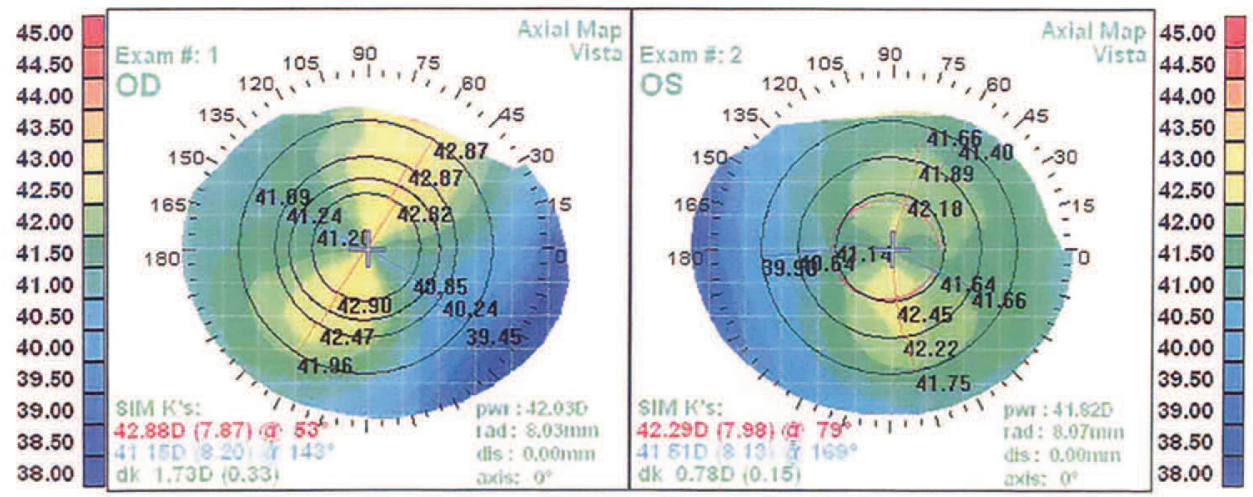

Fig. 1: Preoperative axial map of BE. The LE showing a mild skew deviation (EyeSys Vision, Technologies Inc., Houston, Texas, USA)

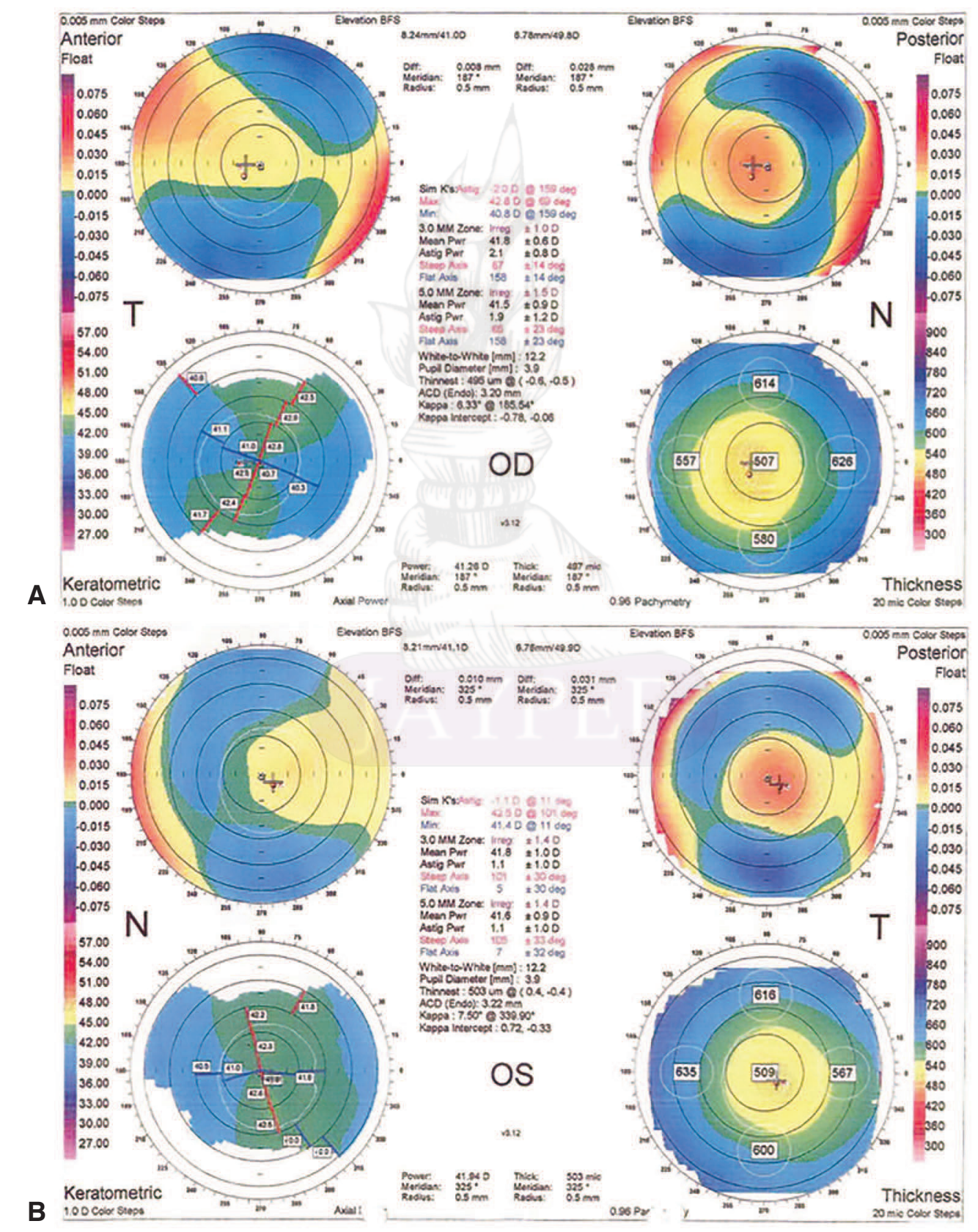

Figs 2A and B: Preoperative Orbscan demonstrating normal values in BE (Orbscan II Bausch and Lomb, Inc., Rochester, NY, USA) 

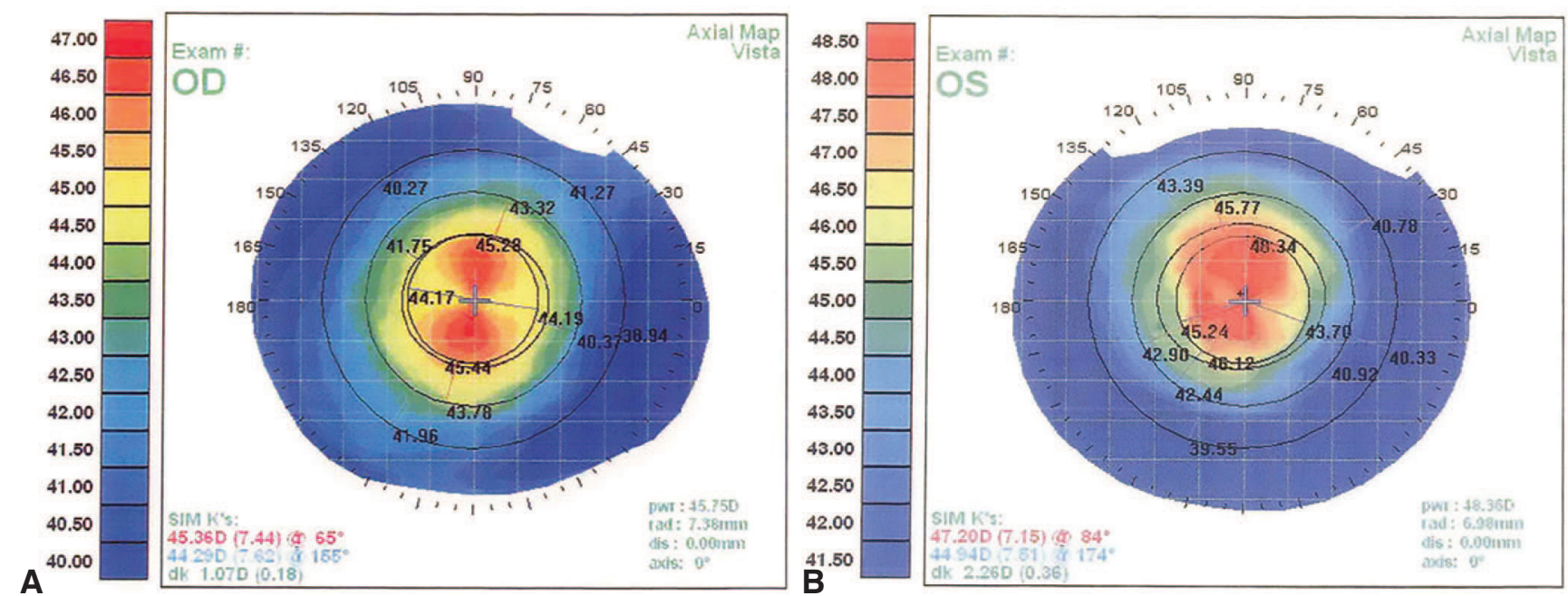

Figs 3A and B: Axial map of BE 16 months postoperatively with normal values in the RE. The LE shows a central steepening with skewed radial axis (EyeSys Vision, Technologies Inc., Houston, Texas, USA)

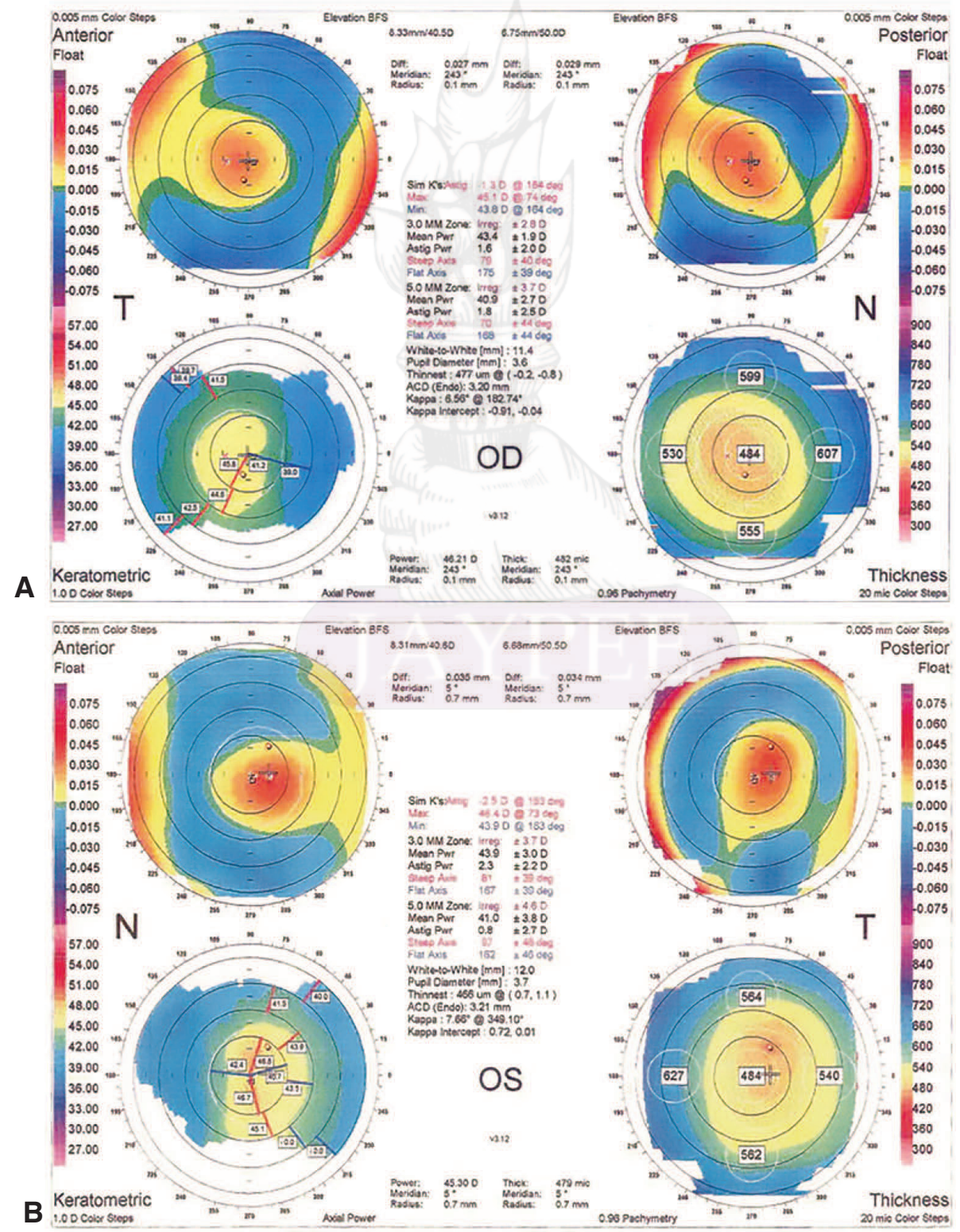

Figs $4 \mathrm{~A}$ and $\mathrm{B}$ : Postoperative topography of the BE 16 months postoperatively, LE showing corneal steepening and increased posterior float elevation (Orbscan II; Bausch and Lomb, Inc., Rochester, NY, USA) 


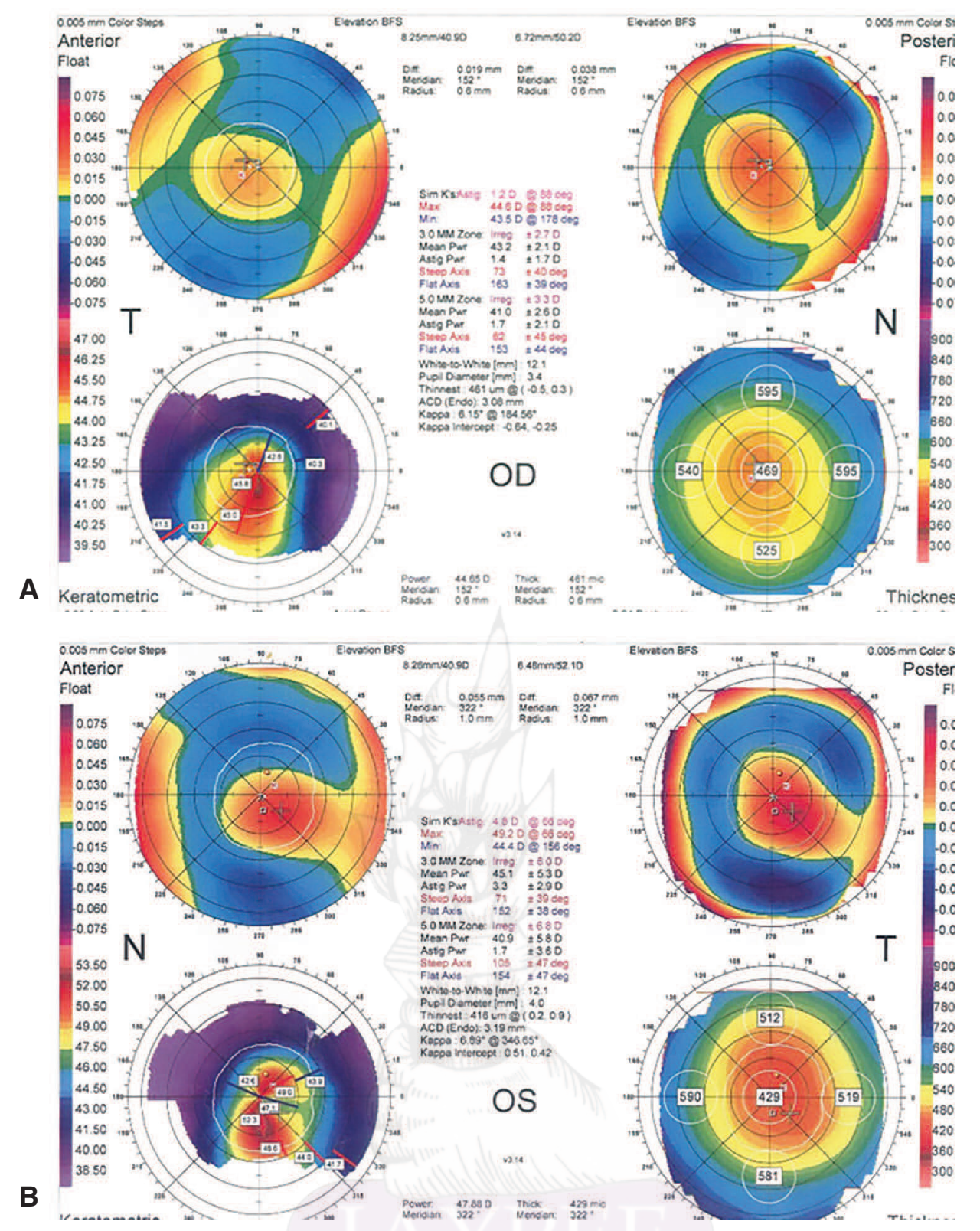

Figs $5 A$ and $B$ : Topography of BE 12 years after initial surgery and 10 years after enhancement, the LE shows increased inferior corneal steepening with pronounced skewed radial axis and significantly increased posterior float elevation (Orbscan II; Bausch and Lomb, Inc., Rochester, NY, USA)

optical zone was of $5.7 \mathrm{~mm}$, the ablation depth was of 39 $\mu \mathrm{m}$. Postoperative UCVA was 6/12+.

Follow-up data were missing until January 2016 when the patient presented to the same facility; UCVA was measured to be $6 / 120$ in the LE and BSCVA of $6 / 15 p$ with cycloplegic refraction of $+0.25 \mathrm{D} 5.25 \mathrm{CD} 145$. Orbscan topography (Orbscan II Bausch and Lomb, Inc. Rochester, New York, USA) showed increased inferior corneal steepening with pronounced skewed radial axis (Fig. 5). Axial map topography (EyeSys Vision, Technologies Inc. Houston, Texas) of the LE shows increased corneal steepening and skew deviation indicative of corneal ectasia (Fig. 6).

In May 2016, the patient presented to our facility. Anterior segment optical coherence tomography (ASOCT, CASIA2, TOMEY, Japan) displayed post-FA-LASIK ectasia in the LE, showing thinning of the cornea and elevation of the anterior and posterior surface of the cornea (Fig. 7). Treatment modalities were then discussed with the patient.

\section{DISCUSSION}

There are numerous reports of corneal ectasia that developed after LASIK in myopic eyes, occurring in most of cases 1 year after surgery, 4,5 although late onset sometimes after 10 years or more has been previously reported. ${ }^{6}$ However, as to reports of corneal ectasia after hyperopic LASIK, few cases have been described in literature: Randleman et al. ${ }^{7}$ reported two cases of post-LASIK corneal ectasia, in one case, early pellucid marginal degeneration was observed preoperatively and 

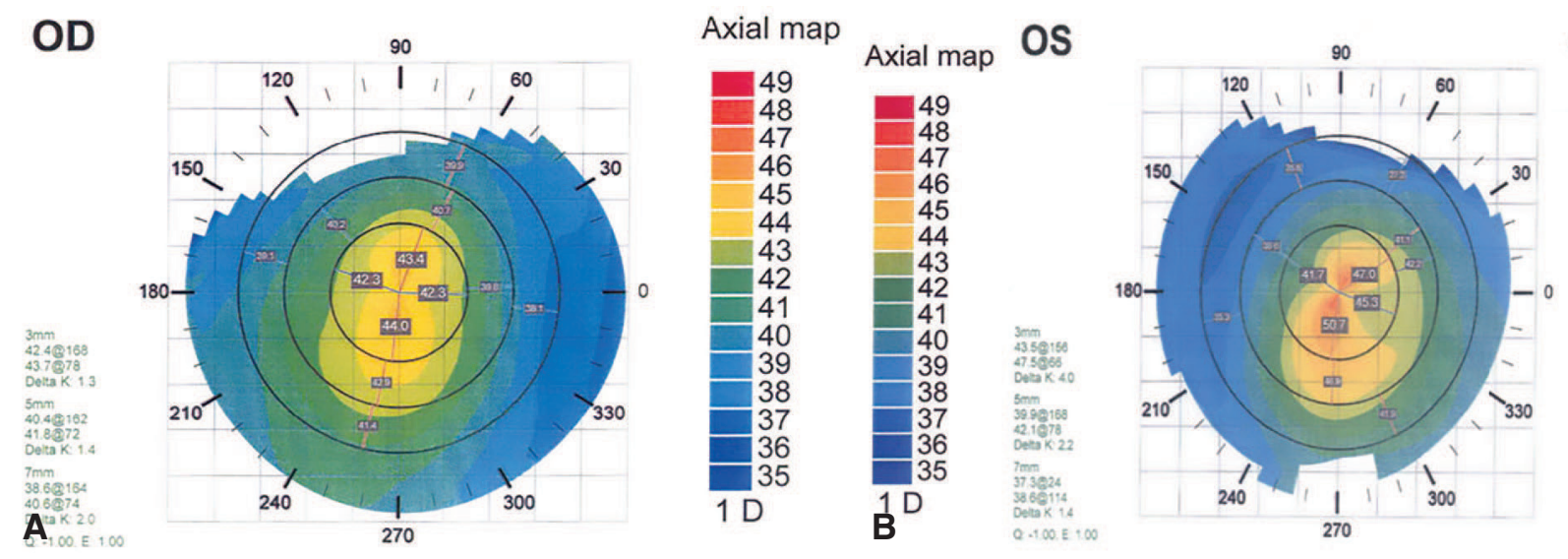

Axial map

Figs 6A and B: Axial map of the LE shows increased corneal steepening and skew deviation indicative of corneal ectasia (EyeSys Vision, Technologies Inc., Houston, Texas)
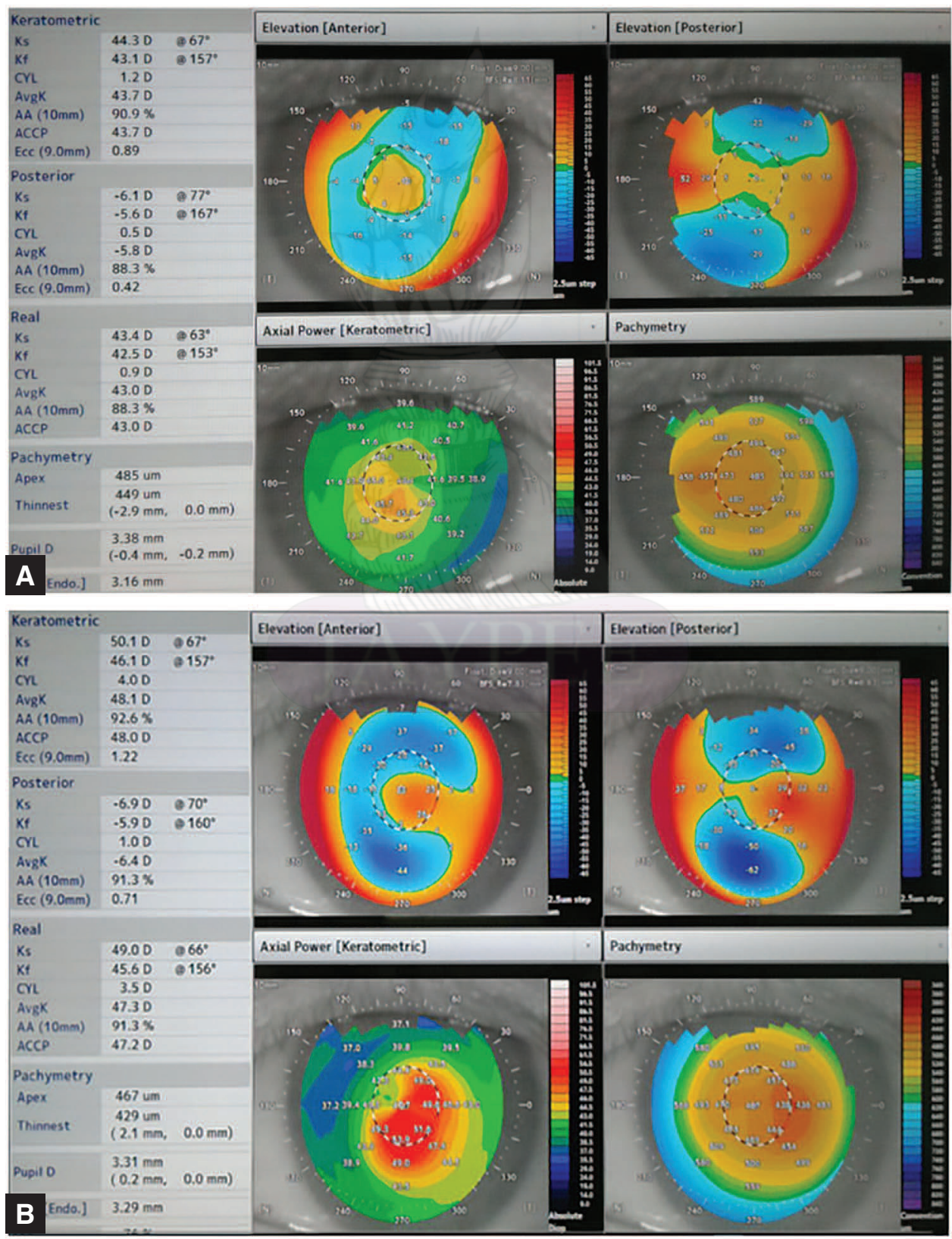

Figs 7A and B: Corneal topography of BE performed by OCT CASIA2. LE showing thinning of the cornea and increase of the anterior and posterior float of the cornea (CASIA2, TOMEY, Japan) 
manifested in corneal topography as inferior steepening in the far periphery. The second case had no preoperative risk factors. Abad et al. ${ }^{8}$ reported on three patients with hyperopic keratoconus which developed ectasia after LASIK following primary hyperopic ablation.

The present case report is distinctive due to the rarity of reported post-FA-LASIK ectasia in general and particularly after hyperopic FA-LASIK, which, to the best of our knowledge, has not been described before.

The rarity of ectasia occurring after hyperopic LASIK may be explained by the fact that the ablation in hyperopic LASIK is performed in the peripheral cornea which is thicker in comparison with the central cornea where ablation is carried out on myopia. The difference between myopic and hyperopic eyes after refractive surgery was described in the study of Shah et al., comparing corneal biomechanical parameters in eyes before and after Excimer Laser refractive surgery. Patients were divided into three groups: myopic patients undergoing laser-assisted-epithelial keratomileusis (LASEK); myopic patients undergoing LASIK; and hyperopic patients undergoing LASIK. Study results showed that corneal hysteresis and corneal resistance factor were found to decrease after refractive surgery in both myopic and hyperopic patients, but the hyperopic LASIK group had a less significant change in biomechanical properties compared with the other groups.

Although the pathogenesis of formation of corneal ectasia after LASIK is not well understood, several risk factors may lead to its development. For example, altered topographic patterns, such as forme fruste keratoconus or pellucid marginal corneal degeneration. ${ }^{3}$ Another risk factor is the percentage of tissue altered (PTA) described first by Santhiago as flap thickness + ablation depth/(CCT). Santhiago et al. ${ }^{3}$ provided evidence that a high value of PTA $(>40 \%)$ was a relevant factor in the development of post-LASIK ectasia in eyes with normal preoperative placido disk-based topography. ${ }^{10}$ However, a recently published study which evaluated the ability of the PTA metric to screen for corneal ectasia after LASIK demonstrated that out of 593 eyes, $21 \%$ had a PTA value of $40 \%$ or more; yet, none of these eyes developed iatrogenic ectasia, suggesting that the PTA metric in its current form may not predict the risk for ectasia after LASIK. ${ }^{11}$ Other risk factors include high myopia with results of lower residual stromal beds (RSB) after appropriate tissue ablation, low preoperative corneal thickness, young age, and multiple enhancements that can lead to residual stromal bed reduction, ${ }^{3}$ low postoperative RSB as a result of excessive flap thickness or deeper than expected stromal ablation. ${ }^{12}$ Furthermore, eye rubbing may cause mechanical progressive changes which lead to ectasia in post-LASIK cornea. ${ }^{13}$ Finally, there is also ectasia without identified risk factors. ${ }^{14}$ All the risk factors mentioned above that were described in the literature referred to myopic eyes. Because of the rarity of posthyperopic LASIK ectasia, no specific risk factors were mentioned regarding this complication. In the present case, the patient initially presented with two risk factors-young age at the time of his first LASIK surgery and mild skew deviation in corneal topography. Low RSB in this case is ruled out because of the high predictability of flap thickness in FA-LASIK. ${ }^{15}$

Currently, there are several available treatments for post-LASIK ectasia, and when ectasia initially occurs, it is possible to offer the patient treatment with corneal collagen cross-linking (CXL) to arrest the progression of corneal ectasia. ${ }^{16,17}$ Rehabilitation of vision is possible by improving VA using correction with glasses or using various types of contact lenses, such as rigid gas-permeable contact lenses, soft keratoconus contact lenses or scleral and semi-scleral contact lenses. Corneal remodeling by intrastromal corneal rings segments (ICRS) that may provide an alternative by allowing additional central corneal flattening with a good refractive outcome and an improvement in UCVA and BCVA. ${ }^{18-20}$ Photorefractive keratectomy (PRK) is an additional treatment modality that may be offered in order to reduce induced myopia and astigmatism. All the above-mentioned treatments may be combined in different sequences, such as simultaneous same day or sequential PRK and CXL treatment or ICRS implantation with sequential CXL treatment. ${ }^{21,22}$

\section{CONCLUSION}

We have presented a rare case of post-femtosecondassisted LASIK corneal ectasia, which developed in a young hyperopic male who initially presented risk factors of mild skew deviation and a relatively young age. In similar cases, a meticulous evaluation of risk factors before surgery can alter management strategies and may prevent the development of corneal ectasia. For at-risk patients, alternative surgical options should be considered including surface ablation and phakic intraocular lenses.

\section{REFERENCES}

1. Seiler T, Quurke AW. Iatrogenic keratectasia after LASIK in a case of forme fruste keratoconus. J Cataract Refract Surg 1998;24(7):100-107.

2. Randleman JB. Post-laser in-situ keratomileusis ectasia: current understanding and future directions. Curr Opin Ophthalmol 2006;17(4):406-412.

3. Santhiago MR, Giacomin NT, Smadja D, et al. Ectasia risk factors in refractive surgery. Clin Ophthalmol 2016;10:713-720.

4. Argento C, Cosentino MJ, Tytiun A, Rapetti G, Zarate J. Corneal ectasia after laser in situ keratomileusis. J Cataract Refract Surg 2001;27(9):1440-1448.

5. Binder PS. Ectasia after laser in situ keratomileusis. J Cataract Refract Surg 2003;29(12):2419-2429. 


\section{IJKECD}

Post-femtosecond-assisted LASIK Ectasia in a Hyperopic Eye

6. Barbara R, Abdelaziz L, Pikkel J, et al. Late onset post-LASIK ectasia. Int J Kerat Ect Cor Dis 2012;1(3):190-195.

7. Randleman JB, Banning CS, Stulting RD. Corneal ectasia after hyperopic LASIK. J Refract Surg 2007;23(1):98-99.

8. Abad JC, Awad A, Kurstin JM. Hyperopic keratoconus. J Refract Surg 2007;23(5):520-523.

9. Shah S, Laiquzzaman M, Yeung I, et al. The use of the Ocular Response Analyser to determine corneal hysteresis in eyes before and after excimer laser refractive surgery. Cont Lens Anterior Eye 2009;32(3):123-128.

10. Ambrósio R Jr, Dawson DG, Belin MW. Association between the percent tissue altered and post-laser in situ keratomileusis ectasia in eyes with normal preoperative topography. Am J Ophthalmol 2014;158(6):1358-1359.

11. Saad A, Binder PS, Gatinel D. Evaluation of the percentage tissue altered as a risk factor for developing post-laser in situ keratomileusis ectasia. J Cataract Refract Surg 2017;43(7):946951.

12. Valbon BF, Ambrosio R Jr, Glicéria J, et al. Unilateral corneal ectasia after bilateral LASIK: the thick flap counts. Int J Keratoconus Ectatic Corneal Dis Int J Kerat Ect Cor Dis 2013;22(22):79-83.

13. McMonnies CW. Mechanisms of rubbing-related corneal trauma in keratoconus. Cornea 2009;28(6):607-615.

14. Klein SR, Epstein RJ, Randleman JB, et al. Corneal ectasia after laser in situ keratomileusis in patients without apparent preoperative risk factors. Cornea 2006;25(4):388-403.
15. Holzer MP, Rabsilber TM, Auffarth GU. Femtosecond laserassisted corneal flap cuts: morphology, accuracy, and histopathology. Invest Ophthalmol Vis Sci 2006;47(7):2828-2831.

16. Richoz O, Mavrakanas N, Pajic B, et al. Corneal collagen cross-linking for ectasia after LASIK and photorefractive keratectomy: long-term results. Ophthalmology 2013;120(7):13541359.

17. Yildirim A, Cakir H, Kara N, et al. Corneal collagen crosslinking for ectasia after laser in situ keratomileusis: long-term results. J Cataract Refract Surg 2014;40(10):1591-1596.

18. Barbara A, Shehadeh-Masha'our R, Garzozi HJ. Intacs after laser in situ keratomileusis and photorefractive keratectomy. J Cataract Refract Surg 2004;30(9):1892-1895.

19. Uceda-Montanes A, Tomás JD, et al. Correction of severe ectasia after LASIK with intracorneal ring segments. J Refract Surg 2008;24(4):408-411.

20. Kymionis GD, Tsiklis NS, Pallikaris AI, etal. Long-term follow-up of intacs for post-LASIK corneal ectasia. Ophthalmology 2006;113(11): 1909-1917.

21. Kanellopoulos AJ, Binder PS. Management of corneal ectasia after LASIK with combined, same-day, topography-guided partial transepithelial PRK and collagen cross-linking: the Athens protocol. J Refract Surg 2011;27(5):323-331.

22. Kamburoglu G, Ertan A. Intacs implantation with sequential collagen cross-linking treatment in postoperative LASIK ectasia. J Refract Surg 2008;24(7):S726-S729. 